\title{
Legiones de pequeños criminales. \\ Percepciones y debates sobre la delincuencia precoz en Buenos Aires, ca. 1890-1920
}

\section{Legions of young criminals. Perceptions and debates about youth delinquency in Buenos Aires, 1890-1920}

\author{
Claudia Freidenraij \\ Instituto de Historia Argentina y Americana “Dr. Emilio Ravignani”, UBA / \\ Conicet \\ "Ciego aquel que no se alarme al ver cómo crece, \\ en medio de la negación de todas las cosas, \\ una generación de pilluelos en cuya mente no germina \\ el temor de la justicia penal ni el de sus agentes"
}

Recibido: 14/03/2017

Aceptado: 28/05/2017

Resumen. Este trabajo se ocupa del problema de la delincuencia precoz y de las formas que se representó en la ciudad de Buenos Aires entre 1890 y 1920. Se analiza, por un lado, los diagnósticos criminológicos sobre la delincuencia infantil de una serie de autoridades en la materia que, en consonancia con la prensa en general, pusieron en circulación discursos altamente alarmistas que advertían sobre el peligro moral -presente y futuro- de un fenómeno en crecimiento. Por otra parte, se busca reponer el lugar que le cupo a las mediciones oficiales de la criminalidad infantil en la elaboración de juicios y prescripciones criminológicas. El objetivo es dar cuenta de la forma en que se construyen los discursos criminológicos, haciendo hincapié en los usos e interpretaciones del aparato estadístico, a la vez que se procura avanzar en una caracterización, a partir de nuestro propio análisis de dicha información, de la

1 "Casa de Educación Correccional y Colonia Agrícola. Proyecto del Dr. Benjamín Dupont del 12/7/1892", Anales del Patronato de la Infancia, vol. 1, 1892, p. 618. 
manera en que se comportó el fenómeno social de la delincuencia precoz a lo largo de los treinta años que constituye el período de estudio.

Palabras clave. Criminología. Delincuencia precoz. Estadística criminal.

Abstract. This work intends to unveil the problem of youth delinquency and the ways that it was represented in the city of Buenos Aires from 1890 to 1920 . It analises, firstly, the criminological diagnoses about youth delinquency from a series of authorities on the issue, who, together with the press, spread highly alarmist discourses through which they would warn about the moral danger - at the time and in the future - of such growing phenomenon. Secondly, the work seeks to restore the role of official youth criminality rates in the elaboration of proceedings and criminological prescriptions. The aim is to show the way criminological discourses are created, by means of repeating and emphasising the interpretation of statistical data, so as to move towards a characterisation, from our own analysis of such information, of the way the phenomenon of youth delinquency behaved throughout the thirty years which constitute the period studied.

Keywords. Criminology. Yough delinquency. Criminal statistics.

Dentro de las claves interpretativas de la cuestión criminal en la Argentina finisecular la creciente amenaza de la delincuencia infantil y juvenil tuvo un lugar destacado ${ }^{2}$. A principios del siglo XX existía el convencimiento de que los delitos cometidos por menores de edad registraban un aumento constante. Era ésta una certeza que atravesaba las páginas de los diarios comerciales, de los magazines ilustrados, de las revistas especializadas en cuestiones criminológicas, de las publicaciones de organismos oficiales (ya fuesen las memorias anuales del Ministerio de Justicia o la Revista de Policía) y alcanzaba las obras de intelectuales ligados a la cuestión criminal, así como las muchas tesis doctorales abocadas a reflexionar al respecto. Ya fuera como premisa para promover nuevas políticas de intervención

\footnotetext{
${ }^{2}$ Las vinculaciones entre delito e inmigración será otro de los tópicos recurrentes dentro de los diagnósticos de las elites. Cfr., entre otros, SCARZANELLA, Eugenia, Ni gringos ni indios. Inmigración, criminalidad y racismo en la Argentina, 1890-1940, Buenos Aires, UNQui, 1999; SOZZO, Máximo, “«Los exóticos del crimen». Inmigración, delito y criminología positivista”, Delito y sociedad. Revista de Ciencias Sociales, Año 20, $\mathrm{N}^{\circ} 32,2011$.
} 
estatal sobre los menores de edad o como enunciado que venía a demostrar la cuantía y la dificultad de la labor ya realizada, la reiteración del argumento del crecimiento constante y continuo de la delincuencia precoz fue absolutamente corriente.

Aunque no todos los diagnósticos sobre la delincuencia precoz coincidían plenamente, sino que reconocían matices y diferencias marcadas en torno al peso que le otorgaban sus mentores a la miseria, la conformación familiar, la 'herencia' degenerativa, el desamparo y el 'abandono' moral de los progenitores, encontramos que la percepción de un aumento de la delincuencia infantil fue un denominador común. Las estadísticas, al traducir numéricamente la magnitud de ese crecimiento, "arrojan bastante luz sobre el mal moral de nuestros menores", argumentaba uno de los especialistas de la época3.

Este trabajo se propone indagar los diagnósticos criminológicos sobre la delincuencia infantil de una serie de autoridades en la materia que, en consonancia con la prensa, pusieron en circulación discursos altamente impresionistas y alarmistas. A su vez, nos interesa poner en tensión esos diagnósticos con la información estadística disponible sobre la delincuencia precoz4. Ello es posible gracias a que, hacia fines del siglo XIX, se generalizó y ganó consenso la idea de que la medición de los males sociales (entre los que se contabilizan el delito, la prostitución, la vagancia, las contravenciones y los suicidios) requería el desarrollo de las "estadísticas morales", cuya ventaja era poner a disposición de las elites fundamentos para trazar juicios morales y justificar acciones políticas5.

$\mathrm{El}$ interés en reflexionar sobre el lugar que ocupan los datos estadísticos en los análisis de los especialistas del mundo del delito, poniendo en contraste los

3 BULLRICH, Eduardo J., Asistencia social de menores, Buenos Aires, Ed. Jesús Menéndez, 1919, p. 120. Tesis presentada a la Facultad de Derecho y Ciencias Sociales de la Universidad de Buenos Aires para optar al grado de Doctor en Jurisprudencia.

4 Existe, pese a los matices, cierto consenso entre los contemporáneos respecto a que las nociones de delincuencia precoz y de criminalidad infantil refieren a un grupo etario que va de los 6 o 7 años a los 18. Pese a la elasticidad de estas nociones en cuanto al sujeto que remiten y más allá de las diferencias que pudiera haber entre niñitos que apenas estaban en condiciones de asistir a la escuela y muchachotes que en muchos sentidos podían considerarse semejantes a un adulto, los contemporáneos encontraron en ese grupo poblacional un distingo respecto de los adultos que infringían la ley, por lo que previeron formas punitivas diferenciales para ellos. Cfr. FREIDENRAIJ, Claudia, La niñez desviada. La tutela estatal de niños pobres, huérfanos y delincuentes. Buenos Aires, ca. 1890-1919, Tesis de Doctorado en Historia, Facultad de Filosofía y Letras, Universidad de Buenos Aires, 2015, p. 44 y ss.

5 DANIEL, Claudia, "Medir la moral pública. La cuantificación policial del delito en Buenos Aires, 1880-1910”, Estatística e Sociedade, № 1, Noviembre de 2011, Porto Alegre, pp. 149-165. 
diagnósticos con sus lecturas del "movimiento criminal", se vincula con la posibilidad de pensar los canales por los cuales determinados temas se convierten en "problemas" que requieren de la atención pública.

Otras investigaciones han señalado ya que las demandas punitivas (cuya historia conoce idas y vueltas, recorta picos y reconoce momentos más álgidos que otros) no siguen de manera directa y lineal a las estadísticas delictivas y que, por lo tanto, es equivocado establecer vinculaciones inmediatas entre las ansiedades sociales y las tasas criminales ${ }^{6}$. Asimismo se ha señalado la imposibilidad de cuantificar el número de menores que cayeron bajo tutela del Estado por la comisión de delitos, por encontrarse en situación de "abandono moral" o por estar deambulando en las calles (circunstancias que asimilaban a los niños en cuestión como sujetos que requerían de la tutela estatal)7. No obstante, estas investigaciones verificaron que "los contemporáneos percibieron esta presencia en las calles como cuantiosa, creciente y amenazante"8.

Se trata entonces de indagar qué usos de las estadísticas criminales se verifican en las obras de algunos de los juristas, criminólogos, penólogos y especialistas en "minoridad" más importantes del período. Nos interesa, particularmente, explorar la forma en que se construyen los discursos criminológicos referidos a la delincuencia infantil y juvenil en referencia a los usos e interpretaciones del análisis estadístico. A su vez, ensayamos un ejercicio de análisis de la estadística disponible a partir de la información recabada en el Anuario Estadístico de la Ciudad de Buenos Aires, con el objetivo de dar cuenta del modo en que se comportó el fenómeno social de la delincuencia precoz a lo largo de los treinta años que constituyen nuestro período de estudio.

6 CAIMARI, Lila, Apenas un delincuente. Crimen, castigo y cultura en la Argentina, 1880-1955, Buenos Aires, Siglo XXI, 2004 y Mientras la ciudad duerme. Pistoleros, policías y periodistas en Buenos Aires, 1920-1945, Buenos Aires, Siglo XXI, 2012.

7 FREIDENRAIJ, Claudia, La niñez desviada. La tutela estatal de niños pobres, huérfanos y delincuentes. Buenos Aires, ca. 189o-1919, Tesis de Doctorado en Historia, Facultad de Filosofía y Letras, Universidad de Buenos Aires, 2015.

8 ZAPIOLA, Carolina, La invención del menor. Representaciones, discursos y políticas públicas de menores en la ciudad de Buenos Aires, 1882-1921, Tesis de Maestría, Buenos Aires, UNSAM, 2007, p. 1. Para el caso de otros fenómenos sociales como el abandono de niños -ciertamente vinculado a éste-, Villalta ha apuntado que si bien varias estadísticas indican un aumento de la cantidad de niños abandonados, "los esfuerzos de las 'elites morales' para establecer sus posiciones no debe comprenderse tanto como el resultado directo de un cambio objetivo en el contexto social sino como fruto de transformaciones en su 'contexto de percepción"”. VILLALTA, Carla, Entregas y secuestros. La apropiación de 'menores' por parte del Estado, Tesis de Doctorado, UBA, 2006, p. 100. 


\title{
Un clima de ideas. Impresionismo y alarma en torno al delito infantil
}

Desde fines del siglo XIX los diagnósticos se reiteraban: el delito infantil, así como el abandono y la vagancia crecían. Existió una tendencia notoria entre funcionarios, filántropos y dirigentes políticos a recurrir a datos numéricos sobre la delincuencia precoz en sus alocuciones públicas con el objetivo de conmover a la audiencia. Las inauguraciones de las obras de caridad y los debates parlamentarios se mostraron como una arena especialmente propensa para que las elites morales diesen rienda suelta a la alarma que teñía sus impresiones sobre la cuestión. En la ceremonia de lanzamiento de su Sala Cuna, el presidente del Patronato de la Infancia instó a la audiencia a no cejar en el esfuerzo por

\begin{abstract}
“combatir un mal social cuyas proporciones son ya aterradoras: mil nuevecientos [sic] niños abandonados han sido inscriptos por faltas en la Policía. Cuatrocientos cincuenta están encerrados en cárceles al lado de malhechores empedernidos y se calcula que más de seis mil hijos de obreros, que no pueden atenderlos, vagan por nuestras calles adiestrándose en la crápula y el vicio. No nos ofusquemos con el brillo de nuestra gran metrópoli, ese germen morboso que aumenta como la marea de las tempestades próximas, dañará al fin nuestras entrañas si rigurosamente no lo estirpamos [sic]"9.
\end{abstract}

La recurrencia al dato numérico siempre impacta. De ahí que se soliese acudir en su auxilio cuando se buscaba conmover al otro, cuando esa conmoción podía producir un resultado político. Eso explica que se manejaran números sin mucho cuidado y en contextos donde el objetivo era concitar la adhesión de los interlocutores. Ya cerrando el siglo, el diputado Carlés arengaba desde la tribuna parlamentaria:

"El tributo con que según la estadística contribuye la población infantil a la vagancia es grande [...] en Buenos Aires llega al 63\%!! [...]. Vemos que en nuestras cárceles el 38 o el $35 \%$ quizás, de detenidos, son menores [...] [Aunque la ebriedad] representa un porcentaje mínimo [de las faltas cometidas], los jóvenes pagan un tributo del $43 \%$ a la ebriedad en general [...]. Un celoso funcionario de policía, con palabra convencida me daba este dato: que el $75 \%$ de prostitutas eran menores" ${ }^{10}$.

\footnotetext{
9 "Inauguración de las Salas Cuna. Discurso del Presidente del Patronato de la Infancia, Francisco P. Uriburu", Anales del Patronato de la Infancia, vol. 3, 1894, p. 634, destacado en el original.

10 "La protección a la infancia en el Congreso. Discurso del diputado Carlés." Anales del Patronato de la Infancia, vol. 7, 1899, p. 291-293, destacado mío.
} 
En su alegato se entremezclaban vagancia, alcoholismo y prostitución, tres fenómenos sociales que en sí mismos no constituían delitos, aunque en su perspectiva sí conducían a él y formaban parte de la "mala vida".

Los diagnósticos sobre la cuestión criminal en la infancia eran altamente impresionistas, esto es, estaban construidos al margen de los datos estadísticos, con dudoso sustento empírico, motivo por el que apelaban con mucha frecuencia a números redondos para ejemplificar; aludían a menudo a incomprobables aseveraciones de ciertos funcionarios públicos como cita de autoridad y recurrían asiduamente a un frondoso anecdotario que remitía a gavillas de niños delincuentes en constante crecimiento. La difusión de esta clase de diagnósticos no quedó reducida a los escritos de los criminólogos y penólogos que publicaban sus opúsculos en revistas especializadas, sino que constituyeron sentencias y (pre)juicios que circularon de manera más generalizada en la prensa diaria, en los magazines ilustrados, en las memorias institucionales y en las publicaciones de distintas agencias estatales. A su vez, esos diagnósticos entremezclaban la cuestión de la delincuencia infantil con otra serie de problemas que se pensaban en tándem: vagancia, abandono, juego. Se producían continuos deslizamientos de sentido entre un universo y otro. En este contexto, en ciertos relatos perdieron fuerza las estadísticas a favor del número redondo y siniestro, que buscaba el pavor del lector, su horrorización, el guiño a cualquier medida de intervención sobre esa población flotante.

La prensa fue un vehículo preferencial de las ansiedades de las elites morales respecto de la "infancia abandonada y delincuente". Los grandes diarios salpicaban sus columnas policiales con hurtos, robos y lesiones protagonizados por niños y jovencitos, que se entrecruzaban con los accidentes en los que los menores oficiaban como víctimas o propiciadores ${ }^{11}$. Estas mostacillas, incrustadas de ordinario en los periódicos de circulación masiva, "por su redundancia cotidiana, vuelve aceptable el

${ }^{11}$ La Nación, 17 de diciembre de 1897, "Menores ladrones". Cfr. la columna de policiales del mismo diario del 12 de noviembre de 1897; del 6 de marzo de 1898; y del 22 de diciembre de 1900. Véase también, a modo de ejemplos, La Nación, 12 de marzo de 1898, "Niño mimoso"; La Nación, 16 de diciembre de 1900, "Un niño de 7 años que mata a un hermanito"; La Nación, 21 de diciembre de 1900, "Dramas infantiles"; La Nación, 14 de enero de 1901, "Suceso sangriento"; Tribuna, 29 de noviembre de 1900, "Menor herido". 
conjunto de los controles judiciales y policíacos que reticulan la sociedad"12. Es decir, horadaron una moralidad desde la cual diagnosticar, juzgar e intervenir sobre la delincuencia infantil (la que no casualmente tenía un claro sesgo de clase). De conjunto, la aparición cotidiana de incidentes de los que participaban menores de las clases trabajadoras en las columnas policiales de los grandes diarios fue sedimentando en la opinión pública cierta noción de que los rateros, los accidentados, los revoltosos, los abandonados, los peleadores y los miserables formaban parte de un mismo problema social, la "infancia abandonada y delincuente".

Los magazines ilustrados confluyeron en los diagnósticos angustiosos sobre la criminalidad infantil publicando reportajes fotográficos que canonizaban a pequeños delincuentes como profesionales del hampa con carreras prometedoras. Estas notas incluían las fotos de frente y perfil de "temibles" menores delincuentes y de "los rateros más celebres de Buenos Aires".

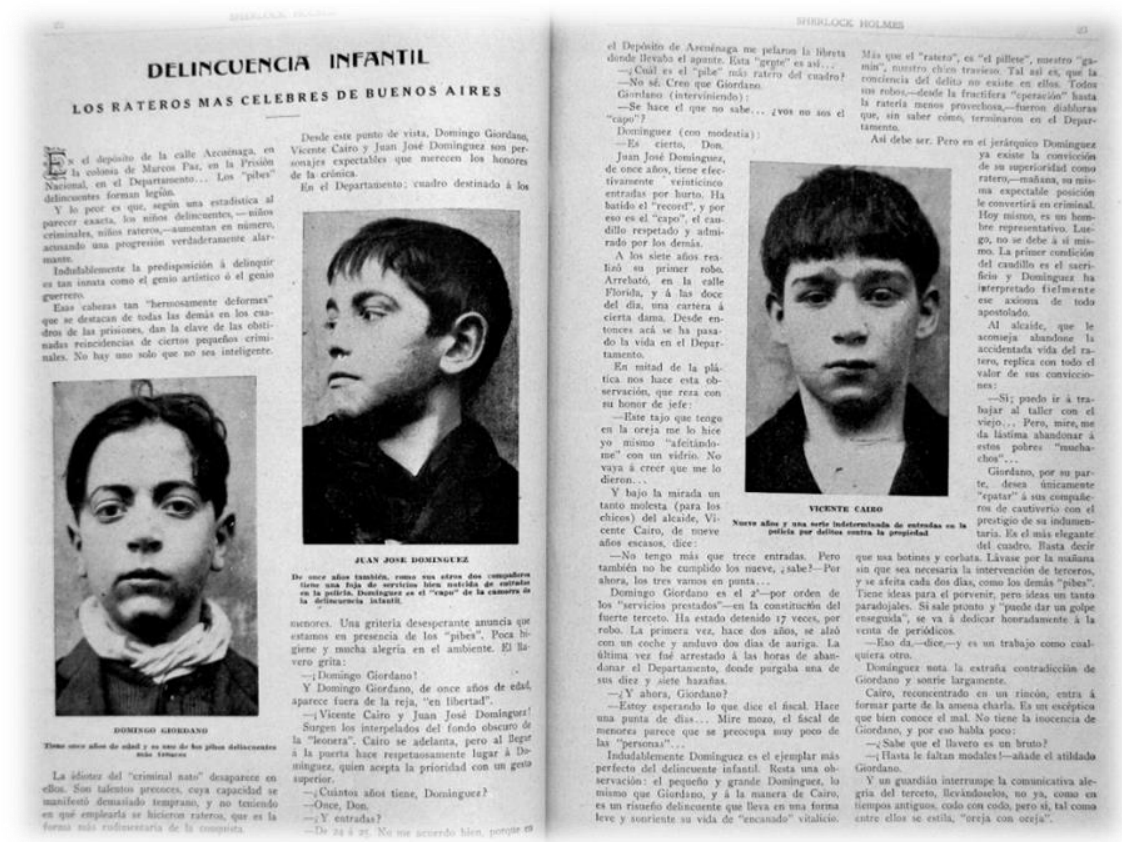

"Delincuencia infantil. Los rateros más célebres de Buenos Aires”, Sherlock Holmes, Año I, $\mathrm{N}^{\circ} 2,11$ de julio de 1911.

12 FOUCAULT, Michel, Vigilar y castigar. Nacimiento de la prisión, Buenos Aires, Siglo XXI, 2006 [1975], p. 292. 



“Los niños delincuentes”. Caras y Caretas, Año XI, Nº 254, 17 de octubre de 1908.

Eran crónicas en primera persona que enfrentaban al lector no sólo con los retratos, filiación completa y alias de los menores delincuentes más avezados, sino que lo alertaban de su amplitud: "es una legión que va tomando proporciones alarmantes y que hace fruncir el ceño en muchas ocasiones a las huestes policiales del coronel Falcón"13. "Los 'pibes' delincuentes forman legión", decía otro reportaje fotográfico más ensañado en mostrar al lector los estigmas degenerativos observables en los primeros planos publicados ${ }^{14}$.

A su turno, los funcionarios públicos también contribuyeron a robustecer el clima de aprensión y temor. Los informes anuales de los Defensores de Menores solían reiterar, sistemáticamente, lo dramático de la situación de los niños y jóvenes a su cargo. "La vagancia y criminalidad de los menores en el municipio de la capital toma un carácter alarmante [...] se requieren medidas urgentes para contenerlas, pues de lo contrario puede ser un peligro social"15. Ese mismo año, su colega de la sección Sud solicitaba explícitamente una reglamentación seria de las leyes atinentes al Ministerio Pupilar, necesaria para intervenir en la realidad criminal:

\footnotetext{
${ }_{13}$ Caras y Caretas, $\mathrm{N}^{\circ}$ 524, 17 de octubre de 1908, "Los niños delincuentes".

14 Sherlock Holmes, $\mathrm{N}^{\circ}$ 2, 11 de julio de 1911, "Delincuencia infantil. Los rateros más célebres de Buenos Aires".

15 Paráfrasis del informe anual del Defensor de Menores de la Sección Norte, Pedro de Elizalde, Memoria del Ministerio de Justicia e Instrucción Pública, Tomo I: Anexos de Justicia 1904 y 1905, Buenos Aires, Talleres Gráficos de la Penitenciaría Nacional, 1906, p. 35.
} 
"Hoy tienen a todos alarmados precisamente esas estadísticas de la criminalidad en la Capital, causando asombro el número de menores que en sus sumas entran. La estadística del último año policial, acusa un 33\% de menores entre los individuos que han sido autores de hechos delictuosos o criminales" 16 .

Esta vez, el diagnóstico era acompañado de la propuesta de creación de dos nuevos asilos para menores dependientes de las defensorías, que estuvieran bajo su administración exclusiva.

Los diagnósticos alarmistas de los funcionarios estatales tenían otra razón de ser: a la vez que justificaban su propia actuación, funcionaban en las memorias institucionales como sostén argumental de sus pedidos hacia la superioridad. Así, se volvió frecuente referir al crecimiento de la criminalidad infantil cada vez que se solicitaba la apertura de nuevos establecimientos de encierro y cuando se buscaban introducir innovaciones en los procedimientos ${ }^{17}$.

La Policía de la Capital fue uno de los actores sociales que más traccionó a favor del consenso sobre el aumento del delito de menores de edad. Ese crecimiento se verificaba no sólo en las estadísticas que ella misma confeccionaba, sino también en sus publicaciones oficiales. En consonancia con la institución policial, los criminólogos también alimentaron esa tendencia a ponderar el delito infantil en tonos de urgencia y alarma, independientemente de las bases empíricas que existían para examinar los alcances del fenómeno criminal ${ }^{18}$. Salvo algunos trabajos más bien excepcionales, las investigaciones criminológicas y de especialistas en derecho penal compartieron ese tinte impresionista, aun cuando entre sus páginas convivieron

${ }_{16}$ Paráfrasis del informe anual del Defensor de Menores de la Sección Sud, Bernabé Láinez, Memoria del Ministerio de Justicia e Instrucción Pública, Tomo I: Anexos de Justicia 1904 y 1905, Buenos Aires, Talleres Gráficos de la Penitenciaría Nacional, 1906, p. 41.

${ }_{17}$ En 1906 Pedro de Elizalde propuso deportar a los Territorios Nacionales al "creciente" número de menores que carecían de adultos que se ocupasen de ellos: "El número de menores vagos, huérfanos o abandonados en esta capital es cada vez mayor, aumentándose con los que llegan del extranjero [...] [estos últimos], en su mayor parte, han sido enviados por sus padres o parientes debido a sus malos hábitos y carencias incorregibles, y una vez llegados a esta ciudad son abandonados por los que los acompañaron, sin recursos ni amparo alguno, y vienen a aumentar los vagos existentes. Evitar este mal que cunde con rapidez es indispensable, y uno de los medios más eficaces es desalojar del municipio este elemento, remitiéndolos a los Territorios Nacionales". Informe del Defensor de Menores de la Sección Norte, en Memoria del Ministerio de Justicia e Instrucción Pública, Tomo I Anexo de Justicia 1906, Buenos Aires, Talleres Gráficos de la Penitenciaría Nacional, p. 102.

18 Un trabajo paradigmático en este sentido es el de José Ingenieros, "Los niños vendedores de diarios y la delincuencia precoz", Archivos de psiquiatría, criminología y ciencias afines, Tomo VIII, 1908, pp. 329-348. Estudio ampliamente citado por los contemporáneos y recuperado por los historiadores gracias a la fama y el respeto del que gozaba su autor, en él se presentan guarismos delictuales sin respaldo documental. 
algunas recopilaciones estadísticas del crimen con otra serie de saberes, más empíricos e inductivos, producidos también por la Policía de la Capital gracias a su tarea de vigilancia y observación del bajo fondo social. Se trataba de casos clínicos, informaciones de vida y costumbres, y estudios antropométricos producidos en los "laboratorios humanos" que se montaron a principios del siglo XX: el Servicio de Observación de Alienados en el Depósito de Contraventores "24 de Noviembre", la Oficina de Estudios Médico-Legales en la Cárcel de Encausados y el Instituto Criminológico en la Penitenciaría Nacional ${ }^{19}$.

Ahora bien, ¿̇realmente creció el delito infantil entre 1890 y 1920? Los contemporáneos estaban convencidos de que así era. Los pocos trabajos históricos que se ocuparon del movimiento criminal entre fines del siglo XIX y principios del $\mathrm{XX}$ coinciden en que se produjo un crecimiento de las tasas delictivas en todo el período, pero no hay demasiadas certezas respecto del alcance de ese aumento y de la naturaleza de los delitos perpetrados. Esto es así por dos motivos. Por un lado, porque la estadística policial (la única existente por entonces y la única con que contamos hoy) exhibe deficiencias técnicas que fueron señaladas ya en su momento por criminólogos y juristas (sobre las que volveremos en breve) ${ }^{20}$. Por otra parte, porque como sostiene Caimari, la estadística delictiva producida por la Policía de la Capital habla más y mejor de la institución que le dio vida, que del universo delictivo en $\operatorname{sí}^{21}$.

19 DANIEL, Claudia, "Medir la moral pública...", ob. cit.; GALEANO, Diego, "Civilización y delito. Notas sobre cuatro criminólogos argentinos", Revista de Historia del Derecho, $\mathrm{N}^{\circ}$ 45, INHIDE, Buenos Aires, Enero-Junio de 2013, pp. 265-277; SALESSI, Jorge, Médicos, maleantes y maricas. Higiene, criminología y homosexualidad en la construcción de la Nación Argentina, 1871-1914, Rosario, Beatriz Viterbo, 1995.

20 Entre los contemporáneos, tanto Antonio Ballvé como Rodolfo Rivarola fueron explícitos detractores de la estadística criminal existente. Cfr. BALLVÉ, Antonio, Primer censo carcelario. Resultados generales, Buenos Aires, Talleres Gráficos de la Penitenciaría Nacional, 1910, p. 7 y RIVAROLA, Rodolfo, Derecho penal argentino, Hijos de Reus, Buenos Aires, 1910, p. 412.

${ }^{21}$ CAIMARI, Lila, Apenas un delincuente..., ob. cit. y Mientras la ciudad duerme..., ob. cit. Otros trabajos que han reparado en las estadísticas criminales como fuente son KIRK BLACKWELDER, Julia y JOHNSON, Lyman, "Changing Criminal Patterns in Buenos Aires, 1890 to 1914", Journal of Latin American Studies, Vol. 14, $\mathrm{N}^{\circ} 2$, 1982, pp. 359-379 y "Estadística criminal y acción policial en Buenos Aires, 1887-1914”, Desarrollo Económico, Nº 93, Vol. 24, Abril-Junio/1984; JONHSON, Lyman (ed.), The Problem of Order in Changing Societies. Essays on Crime and Policing in Argentina and Uruguay, 1750-1940, University of New Mexico Press, 1990; SALVATORE, Ricardo, "Los crímenes de los paisanos: una aproximación estadística", Anuario del IEHS "Prof. Juan Carlos Grosso", No 12, Tandil, UNCPBA, 1997, pp. 91-100 (una nueva versión fue publicada bajo el título de "Los delitos de los paisanos" en SALVATORE, Ricardo, Subalternos, derechos y justicia penal. Ensayos de historia social y cultural argentina, 1829-1940, México, Gedisa, 2010) y "Patrones de sentencias en la 
Aunque hubo una marcada preferencia por parte de los criminólogos argentinos por realizar trabajos de corte más bien etnográfico, un impulso de “indagación empírica” -la genuina preocupación por dar cuenta de la realidad social sobre la que les tocaba intervenir- llevó a algunos de ellos a enfrentarse a esas estadísticas delictivas, aun con sus falencias y omisiones ${ }^{22}$. Los estudios de Miguel Lancelotti, Roberto Gache y Eduardo Bullrich iban en ese sentido ${ }^{23}$. Los tres coincidían en que el aumento de la criminalidad en Buenos Aires podía interpretarse como el precio pagado por la modernidad urbana, el efecto no querido del avance civilizatorio de la gran urbe, cosmopolita y rica. La explosión demográfica que sufrió Buenos Aires desde las últimas dos décadas del siglo XIX se halla entre los argumentos de los tres criminólogos; aunque, como veremos en el apartado siguiente, ninguno explica el aumento de la criminalidad apelando al crecimiento demográfico.

\section{La estadística sobre la criminalidad infantil}

El estudio de Miguel Lancelotti, La criminalidad en Buenos Aires, fue uno de los primeros trabajos que buscaba trazar la evolución de la criminalidad en la capital de la Nación a lo largo del cuarto de siglo que va de 1887 a $1912^{24}$. En un contexto de

Argentina moderna, 1878-1948”, II Jornadas Nacionales de Historia Social, La Falda, Córdoba, Mayo de 2009; SOZZO, Máximo, “«Los exóticos del crimen». Inmigración...”, op. cit.

${ }_{22}$ Sobre la emergencia de una etnografía del bajo fondo porteño, véase SALVATORE, Ricardo, "Usos científicos en La mala vida de Eusebio Gómez" en Osvaldo BARRENECHE y Ricardo SALVATORE, El delito y el orden en perspectiva histórica, Rosario, Prohistoria, 2013, pp. 99-120. Un análisis más amplio en términos historiográficos de la criminología argentina del cambio de siglo en GALEANO, Diego, "Civilización y delito...", op. cit.

${ }^{23}$ LANCELOTTI, Miguel A., La criminalidad en Buenos Aires, al margen de la estadística (1887 a 1912), Córdoba, Buena Vista Ed., 2012 [1912]; GACHE, Roberto, La delincuencia precoz, Buenos Aires, J. Lajouane \& Cía., 1916; BULLRICH, Eduardo J., Asistencia social de menores, ob. cit.

${ }_{24}$ Otros trabajos habían abordado tangencialmente la cuestión antes. Antonio Dellepiane incluyó en su temprana tesis Las causas del delito un capítulo en el que reconstruye el movimiento criminal en los diez años que van de 1881 a 1891. También Antonio Ballvé, Director de la Penitenciaría Nacional y de la Revista de Policía, publicó en sus páginas una nota acerca de la delincuencia en la ciudad de Buenos Aires en los diez años que median entre 1897 y 1906, en base a la información recogida en el primer censo carcelario levantado en 1906 gracias a su iniciativa, cuyos datos duros fueron el insumo utilizado por Eusebio Gómez en La mala vida en Buenos Aires (1908). Estos estudios fragmentarios habían trazado una primera aproximación al movimiento criminal general. Dellepiane sostuvo -retomando algunas de las conclusiones de Francisco Latzina derivadas del Censo de la Ciudad de Buenos Aires de 1887- que la delincuencia se había mantenido estable en el período 1881-1887 (lo que implicaba un descenso real, conforme el aumento poblacional operado en el período), fenómeno que se habría revertido a partir de 1888 cuando comenzó a registrarse un crecimiento rápido y gradual de la delincuencia general en la Capital de la República. Por su parte, los guarismos expuestos en el trabajo de Ballvé "encierran toda una novedad": mientras la población aumentó, aproximadamente, en un 30\% en el período 1897-1906, el delito se mantuvo en términos absolutos, lo cual implicaba una disminución en términos relativos. Para Ballvé, el hecho de que en 1903 se haya producido una inflexión a la baja, se vinculaba con la sanción del nuevo código penal, que endurecía las penas y aumentaba la represión, reconociendo explícitamente la eficacia de un código que había sido 
enorme transformación (demográfica, urbanística, social, económica, cultural) de la ciudad de Buenos Aires, la criminalidad crecía, así como la reincidencia: la modernización era el escenario en el que se disparaban los índices delictivos que preocupaban a sociólogos, criminalistas y hombres de gobierno de todo el mundo: "Buenos Aires no ha escapado a este triste privilegio"25. Sin embargo, argumentaba Lancelotti, la explosión demográfica no era el factor explicativo del crecimiento criminal: mientras la población se había triplicado entre 1887 y 1912, la cantidad de delitos se había multiplicado por siete en el mismo lapso.

La cuestión que revestía mayor gravedad para el autor era la criminalidad de los menores, "cuyas cifras han alcanzado en estos últimos tiempos un abultamiento inesperado" (p. 51). Aunque reconocía que éste era un fenómeno general, vinculado a "la vida moderna", común a todos los países, afirmaba que "en ninguna parte el mal ha alcanzado, como entre nosotros, proporciones más alarmantes, ni ha sido más descuidado por la familia, por la sociedad y hasta por las autoridades" (p. 51). Según el autor, esto quedaba demostrado a partir de las cifras absolutas de delitos cometidos por menores de edad que recogía en el siguiente cuadro:

\section{Cuadro y Gráfico 1. Menores criminales aprehendidos}

\begin{tabular}{|l|c|c|c|c|c|c|c|}
\hline & 1887 & 1892 & 1897 & 1902 & 1907 & 1911 & 1912 \\
\hline $\begin{array}{l}\text { Menos de } \\
16 \text { años }\end{array}$ & 76 & 236 & 406 & 471 & 380 & 428 & 452 \\
\hline $\begin{array}{l}\text { Entre 16 } \\
\text { y 20 años }\end{array}$ & 295 & 682 & 958 & 966 & 1175 & 1277 & 1312 \\
\hline
\end{tabular}

duramente criticado. Cfr. DELLEPIANE, Antonio, Las causas del delito, Buenos Aires, Imprenta de Pablo Coni e Hijos, 1892, Tesis para optar al grado de Doctor en Jurisprudencia, Facultad de Derecho y Ciencias Sociales; BALLVÉ, Antonio, "La criminalidad en la Capital en los últimos diez años", Revista de Policía, $\mathrm{N}^{\circ}$ 233, 1 de febrero de 1907.

${ }_{25}$ LANCELOTTI, Miguel A., La criminalidad en Buenos Aires... ob. cit., p. 41 [todas las citas fueron tomadas de la edición de 2012]. Este trabajo fue publicado originariamente en forma de artículo en la Revista Argentina de Ciencias Políticas dirigida por Rodolfo Rivarola en junio de 1912. Una segunda versión ampliada se publicó en las páginas de la Revista de Criminología, Psiquiatría y Medicina Legal dirigida por Helvio Fernández en enero de 1914. Ese mismo año, la editorial de Valerio Abeledo publicó este estudio en forma de libro. 


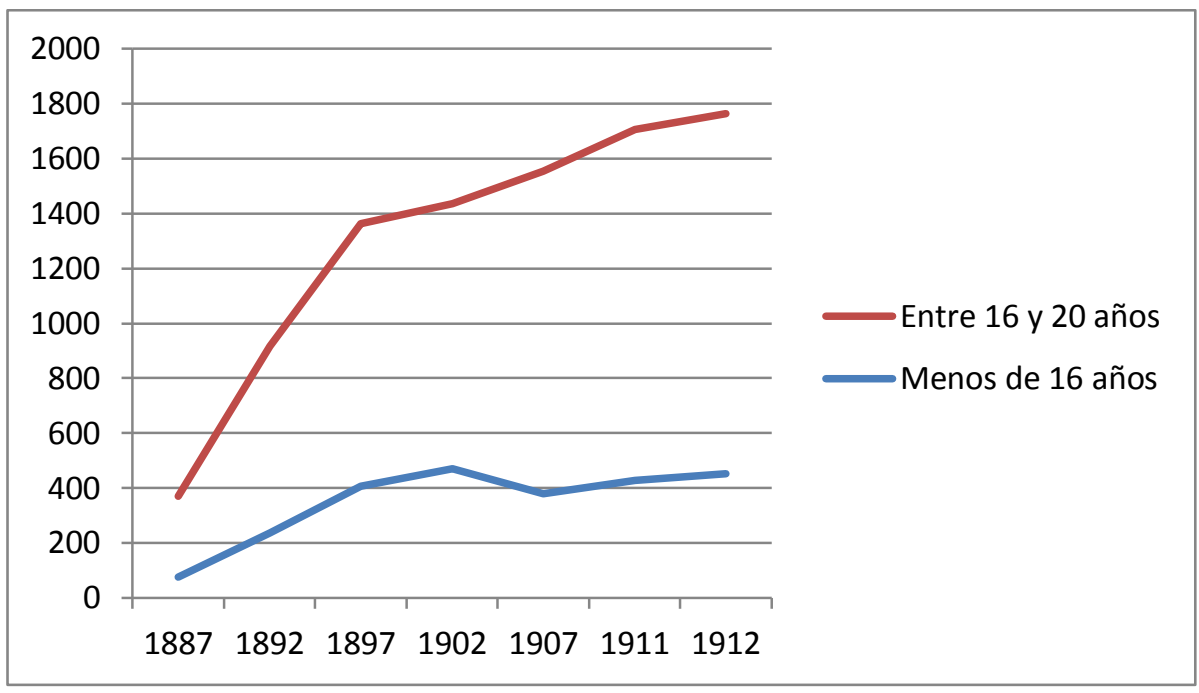

Fuente: elaboración propia en base a los datos suministrados por Lancelotti, op.cit., p. $53^{26}$.

Lancelotti acompañaba estas cifras diciendo:

"Desde 1887 a este último año [1912] el crecimiento de esta clase de delincuencia ha sido siempre continuo, sin que nada, absolutamente nada se hubiera hecho para impedir que dos mil niños apenas salidos de la pubertad fueran anualmente a aumentar el contingente ya numeroso de nuestras cárceles" (p. 53).

El gráfico precedente pone de manifiesto la amplia brecha existente entre menores con más de 16 años aprehendidos por la policía, respecto de los menores de esa edad. Pero oculta el hecho de que la proporción de crecimiento de esas aprehensiones es superior para los menores de 16 años que para los mayores, si se tiene en cuenta los valores de 1887 y 1912 ( 1 a 5.09 en el primer caso y 1 a 4.44 en el segundo).

Es llamativo que, incluso en estas obras, donde el dato estadístico ordenado y sistematizado es la piedra angular de la argumentación, se recurra a otros números menos confiables, pero tanto o más efectivos. Lancelotti sostenía que, entre 1903 y 1912 más de 15 mil menores de edad habían sido aprehendidos por la policía. Constituían, en promedio, el $28 \%$ del total de los delincuentes aprehendidos ${ }^{27}$. Y continuaba:

${ }^{26}$ Lancelotti no explicita en ningún momento de dónde recoge estos datos, pero coinciden con los apuntados en el Anuario Estadístico de la Ciudad de Buenos Aires, que obran como apéndice de su trabajo.

${ }_{27}$ Los datos desagregados indican que, en promedio, los menores de 16 años constituían el 7,4\% de los sujetos aprehendidos, mientras que los que contaban entre 16 y 20 años, alcanzaban el 20,7\%. 
"Durante ese mismo período había en Buenos Aires no menos de 5.000 niños vagabundos; 5.00o niños, según los datos de la misma policía, sin casa, sin hogar, sin instrucción, sin nada; 5.000 niños que vivían en la calle y por la calle [...]. Hay en la actualidad más de 10 mil niños que viven en el ocio, sin moral, sin religión, sin pudor". (pp. 68-69).

La fuente era un suelto del diario La Nación del 6 de febrero de 1907. A veces, el número redondo tomado a la ligera de un diario de circulación masiva interpelaba de manera más eficaz que un concienzudo análisis estadístico.

En 1916, Roberto Gache publicó la que posiblemente sea la tesis doctoral más sofisticada y con mayor elaboración de la época acerca de la delincuencia infantil y juvenil en Buenos Aires. Allí, parte de la premisa de que el estudio cuantitativo de la delincuencia infantil no sólo está obstaculizado por las deficiencias de la información estadística, sino que también sufre alteraciones por la deficiencia de la represión del delito $^{28}$. A pesar de esas limitaciones, Gache hace un uso bastante más extensivo de la información estadística que muchos de sus contemporáneos, justamente gracias a sus incursiones en el universo carcelario y de la justicia de menores ${ }^{29}$. Es llamativo que mientras la mayor parte de los diagnósticos de los contemporáneos estaban basados en sus impresiones personales sin apoyaturas demasiado firmes, Gache haya sido mucho más cauto a la hora de calibrar la magnitud del problema.

Mirada en el tiempo, la estadística de la delincuencia de menores de 16 años no revela aumentos sensibles a partir de 1900 hasta 1915, aunque sí entre los delincuentes de entre 16 y 20 (exclusive) años: "el verdadero peligro de nuestra delincuencia -dice Gache- está en la de las mayores edades” (p. 96).

\footnotetext{
${ }_{28}$ GACHE, Roberto, La delincuencia precoz... ob. cit., pp. 92-93. Esto significaba, que un "número enorme de delitos queda impune", ya fuera porque sus autores pertenecían a familias pudientes que indemnizaban al damnificado; porque se trate del ratero astuto que permanece invisible al celo policial o, al contrario, por tratarse del "ratero vulgar en estado perpetuo de delincuencia 'latente', que por conocido -aunque parezca paradoja- escapa a la acción policial”.

${ }_{29}$ Dice Gache: "Gran parte de los datos numéricos, porcentajes y estadísticas especializadas han sido recogidos de sus mismas fuentes y ordenadas por mí mismo. Aparte de los libros del Asilo Correccional de Mujeres, de la Cárcel de Menores de La Plata, de la Colonia de Menores de Marcos Paz y del Departamento de Menores encausados anexo al Cuerpo de Guardia de Cárceles de esta capital, he revisado en estos dos últimos establecimientos más de 600 prontuarios de jóvenes detenidos en diversas épocas. Debo, en fin, a la Policía de la Capital, algunas importantes estadísticas generales de Delincuencia de Menores, las primeras, por lo demás, que esta institución ha preparado sobre el particular, sin darlas aun a publicidad” (p. 13). A pesar de que no sabemos cuáles son esas estadísticas inéditas, la tesis de Gache se destaca entre la de sus pares por su consistencia, su originalidad y la seriedad del trabajo que hay detrás.
} 


\section{Cuadro y Gráfico 2. Término medio anual de delitos cometidos por menores, 1882-1913}

\begin{tabular}{|c|c|c|c|}
\hline & $\begin{array}{l}\text { Men } \\
\text { ores de } 16 \text { a } \\
20 \text { años }\end{array}$ & $\begin{array}{l}\text { nores } \\
16\end{array}$ & $\begin{array}{r}\mathrm{Me} \\
\mathrm{de}\end{array}$ \\
\hline 882 & 216 & & 51 \\
\hline 885 & 226 & & 45 \\
\hline 888 & 403 & & 60 \\
\hline 890 & 570 & & 87 \\
\hline 900 & 880 & 4 & 42 \\
\hline 905 & 109 & 1 & 39 \\
\hline 911 & 1366 & 6 & 47 \\
\hline 912 & 1396 & 8 & 50 \\
\hline 913 & 1571 & 4 & 49 \\
\hline
\end{tabular}

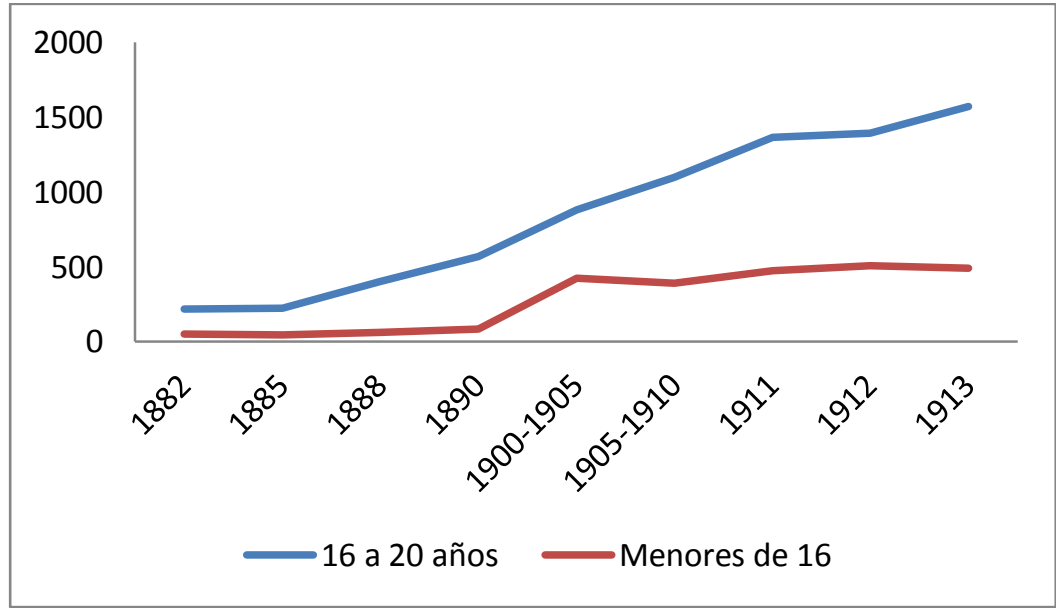

Fuente: elaboración propia en base a los datos suministrados por Gache, op. cit., pp. 96-99.

Estas cifras vendrían a demostrar, afirma Gache, que de 1890 a 1900 "la delincuencia 'infantil' (edades menores de 16 años) aumenta bruscamente (87 a 424), para mantenerse luego [...] estacionaria. Aquella brusca progresión refleja exactamente el concomitante desarrollo, igualmente repentino de nuestro urbanismo". Y agregaba en una extensa nota al pie que Antonio Dellepiane le había hecho notar que el brusco aumento producido entre 1890 y 1900 coincidía con la implantación de la Ley 1420 "por lo que no vacila en correlacionar la modificación [en la legislación educativa] con el aumento anotado de la delincuencia infantil" 30 . Sin embargo, Gache insistía en su argumentación en la importancia crucial del

$3^{30}$ La Ley 1420 sancionada en 1884 establecía la obligatoriedad de la educación para todos los niños y niñas entre los 6 y los 14 años, así como su gratuidad y laicidad. Esta legislación fue la piedra angular del sistema educativo argentino y el puntapié de un proceso de escolarización masiva que redujo drásticamente los índices de analfabetismo. 
urbanismo, un término que refería tanto a "una transformación puramente material de la 'gran aldea", como a la "intensificación y complicación de vida, ese entrecruzamiento de fuerzas e intereses diversos en acción [y a] ese desarrollo del pauperismo" (p. 100).

Finalmente, la tesis de Eduardo Bullrich de 1919 encuentra vigorosos puentes con la de Gache, en parte porque años antes habían trabajado juntos en la redacción de un proyecto de Código de Menores que nunca se concretón ${ }^{31}$. Sus producciones académicas coinciden en la caracterización de la "infancia abandonada y delincuente" como resultado de las contradicciones sociales; en el énfasis puesto en el ambiente social en que se desarrolla el menor para explicar su conducta (en detrimento de las explicaciones que ponen el peso en cuestiones vinculadas a la "herencia" criminal) y en la incorporación de un detallado análisis de "las deficiencias de los resortes judiciales, policiales y carcelarios" como un argumento central para explicar el fenómeno de la delincuencia precoz ${ }^{32}$.

Pese a estas gruesas coincidencias, Bullrich difería explícitamente de las lecturas estadísticas de la criminalidad infantil de Gache. Según su valoración, "el aumento progresivo del mal no es grande, sobre todo en cuanto a los menores de 16 años", si se exceptúa la última década del siglo XIX (cuestión que explicaba recurriendo a una vuelta de tuerca del argumento de Dellepiane respecto a la negativa influencia de la Ley 1420, "que al sustituir la educación religiosa determinó un relajamiento en la moral de los menores"). Sin embargo, sí encontraba importante el coeficiente de la delincuencia en relación a la población por franja etaria (p. 95, destacado mío).

"Las estadísticas, para ser útiles, tiene que ser relativas, y tienen sobre todo, que ser manejadas con mucha prudencia” (p. 96), afirmaba Bullrich. Por eso calculó la cifra relativa de la delincuencia de menores por franja de edad (menores de 16 años y menores de entre 16 y 20 años) teniendo en cuenta la población existente en cada una de ellas. El resultado fue que entre 1900 y 1917 la relación entre la cifra absoluta de delincuentes menores de 16 años y el total de la población osciló entre 2,1\%o

${ }_{31}^{1}$ BULLRICH, Eduardo J. y GACHE, Roberto, Código de menores. Anteproyecto e informe presentado al Señor Ministro de Justicia e Instrucción Pública Dr. Carlos Saavedra Lamas, Buenos Aires, Talleres Gráficos de la Penitenciaría Nacional, 1916.

${ }^{2}$ BULLRICH, Eduardo J., Asistencia social..., ob. cit., p. 37. 
(1900) y el 1,5\%o (1917); la misma relación para la franja etaria de entre 16 y 20 años anduvo entre el 11 y el 10\%o para las mismas fechas. Esto le permitió concluir que "el aumento [de la delincuencia de menores] no es sensible ni para los menores de 16, ni para los de 16 a 20 años; más bien la relación oscila entre un máximo y un mínimo; pero justamente el peligro está en esos coeficientes demasiados elevados, y que explican el aumento de la criminalidad de los individuos de 20 a 25 años, que, de 1913 a 1917, han pasado a engrosar las filas de los delincuentes mayores" (p. 98).

Lo interesante de estos guarismos es que no verifican el tan recalcado crecimiento de la delincuencia infantil a lo largo del período considerado, sino más bien un estancamiento para una y otra franja de edad, siempre que se calcule en relación a la población correspondiente. Asimismo, es llamativa la distancia entre esas cifras de delincuentes "comprobables" y las que Bullrich califica como "en peligro". Sumados, estos niños y jóvenes delincuentes no superan nunca el 13\%o de la población de su edad; sin embargo, el universo "en peligro" era calculado en el 25\%o de la población de menor edad. Así, razonaba Bullrich:

\footnotetext{
"iQue de cada mil menores de 16 a 20 años, haya 10 delincuentes detenidos y procesados, se traduce que la cantidad de los que están en peligro moral ha de ser muy grande, si se piensa que una gran parte de los menores consigue eludir la acción policial y que otros, no considerados como delincuentes por la actual legislación se hallan en peligro moral inminente o en un estado peligroso de vacío moral; en tal circunstancia pueden colocarse a los vagos, viciosos o no, mendigos profesionales u ocasionales y abandonados en general, y el mal irá adquiriendo contornos siniestros! Casi podría calcularse en $25 \%$ la cifra de menores vagos y abandonados (en relación a la población de la edad) iY esto sin tener en cuenta la prostitución de los menores [!]” (p. 99).
}

El análisis de estos tres estudios más centrados en la evidencia estadística permiten advertir, en primer lugar, que incluso los trabajos más serios basados en el aparato estadístico no necesariamente excluyen el uso de otros datos y fuentes de información de carácter impresionista, cuya eficacia parece haber sido mayor. En segundo lugar, que las mediciones del delito reconocen una amplia variabilidad según se realicen en términos absolutos o relativos y, finalmente, que el uso de las mismas fuentes estadísticas puede generar interpretaciones divergentes del mismo fenómeno. De conjunto, estas consideraciones deberían bastar para ponernos en sobreaviso respecto de un supuesto carácter 'neutro' o ‘científico' de los datos cuantitativos. 


\section{La producción de la estadística sobre la delincuencia precoz}

A fines del siglo XIX se organizó en la Capital de la República una repartición ocupada de recoger la información estadística disponible (y de promoverla allí donde todavía no existía) relativa a un sinfín de aspectos de la vida social de la ciudad de Buenos Aires. La Dirección de Estadística Municipal fue creada en 1887 y desde 1891 editó el Anuario Estadístico de la Ciudad de Buenos Aires (en adelante, Anuario)33.

El Anuario se interesaba por un enorme repertorio de cuestiones. En sus páginas convivían los datos relativos a la demografía, la situación sanitaria, los fenómenos climáticos, el análisis químico y bacteriológico del aire, la inspección de mercados y ferias, la alimentación pública, los medios de locomoción y comunicación, el movimiento económico (que distinguía lo relativo a los inmuebles, bolsa de valores, sociedades anónimas, comercio exterior, finanzas municipales e instituciones bancarias), la estadística electoral, la instrucción pública, las diversiones y el juego. En medio de toda esta vorágine informativa, el "movimiento criminal" y el "movimiento carcelario" también tuvieron su espacio. La estadística servía, al decir de los funcionarios encargados de ella, a "altos propósitos de administración y de progreso científico"34.

La sección del Anuario dedicada al movimiento policial y criminal era producida por la oficina de estadística de la Policía de la Capital. La tradición policial de recolección de datos y mediciones cuantitativas del bajo fondo porteño se había iniciado hacia 1875, cuando el Jefe de Policía resolvió crear una oficina a tales efectos. Desde entonces se puso en marcha una "empresa de objetivación estadística de las distintas manifestaciones de la 'mala vida' urbana” que, no sin tensiones ni objeciones, constituyó la base estadística disponible para quienes estaban interesados en observar el mundo del delito35. En 1891, cuando se publicó el primer Anuario, los comentarios sobre los datos relativos al movimiento general de la delincuencia de la

33 GONZALEZ BOLLO, Hernán et al., 125 años de la estadística porteña, Ciudad de Buenos Aires, Gobierno de la Ciudad Autónoma de Buenos Aires. Dirección General de Estadísticas y Censos, 2015.

34 MARTínEZ Alberto B., Anuario Estadístico de la Ciudad de Buenos Aires, Buenos Aires, Imprenta La bonaerense, 1908, p. xiii.

35 DANIEL, Claudia, “Medir la moral pública...”, op. cit., p. 152. 
ciudad de Buenos Aires, que referían a la última década, estuvieron a cargo del Dr. Antonio Dellepiane ${ }^{36}$.

El hecho de haber sido la Policía la encargada de producir la estadística criminal contribuyó en gran medida a la endeblez de la base de las "estadísticas morales", tanto en términos técnicos como en cuanto a la legitimidad de la que gozaron ${ }^{37}$. Como ha demostrado Daniel, la estadística criminal recibió numerosas críticas: desde variaciones sistemáticas, año a año, en la forma de compilar la información hasta las "cegueras selectivas" expresadas en el registro diferencial de delitos informado por criterios de clase y procedencia social, pasando por la omisión del registro de reincidencias. La producción de lecturas direccionadas del fenómeno criminal ${ }^{8}$, así como la desconfianza respecto de su capacidad para expresar las complejidades del fenómeno que decía traducir, hicieron que abogados y juristas cuando no criminólogos, políticos y funcionarios públicos de diverso calibre"ubicaran esas cifras como un conocimiento de segundo orden, de devaluada jerarquía” 39.

No fueron pocos (ni marginales) quienes alzaron la voz para deslegitimar la estadística criminal existente. Al proponer al Gobierno la realización del Primer Censo Carcelario Nacional, Antonio Ballvé argumentó que quienes hubiesen querido practicar cualquier clase de estudios relacionado con la ciencia penal

\footnotetext{
${ }^{36}$ Advertía Dellepiane en su tesis doctoral Las causas del delito de 1892, que era escasa la atención que había despertado la estadística criminal en la Argentina entre los hombres de ciencia, lo cual se explicaba, en parte, por la carencia de oficinas de estadística de carácter nacional. Para su investigación, Dellepiane había tenido que atenerse a las estadísticas que llevaban los Departamentos policiales de la Capital y de algunas otras ciudades (como Córdoba y Rosario), cuya acumulación en la última década permitía, al menos, ensayar "hipótesis menos inverosímiles sobre el movimiento de la criminalidad en Buenos Aires”. DELLEPIANE, Antonio, Las causas del delito..., ob. cit., p. 276.

37 La mayor parte de las agencias europeas de estadística criminal no recababan sus datos de la institución policial, sino de las decisiones del poder judicial y las constancias de los procesos. DANIEL, Claudia, "Medir la moral pública...", ob. cit., p. 158.

${ }^{38}$ Las lecturas direccionadas en un sentido u otro, según la argumentación de quien efectúa el análisis, es absolutamente corriente y puede hacerse con un grado mayor o menor de sofisticación y recato. Lo cierto es que no todos han sido burdos intérpretes de los datos disponibles, pero incluso alguno de los más prolijos analistas han derrapado en sus argumentos. Tal fue el caso de Bullrich, quien al explicar los guarismos sobre contravenciones de menores de edad del sexo femenino sostiene que "casi todas [...] pueden ser consideradas como cometidas por menores prostituidas (...) No pueden tener otra explicación las 25 entradas por ebriedad, las 58 [sic] por escándalo, las 54 por desorden, 1 por porte de armas y 7 por mendicidad" (BULLRICH, Eduardo J., Asistencia social..., ob. cit., p. 120 y 122, destacado mío). Incluso en un observador agudo como él los prejuicios (en este caso de género) nublaban su juicio: ciertas conductas manifestadas en niñas y jovencitas eran indicadores inequívocos de prostitución, independientemente de lo que su base estadística le permitiese afirmar.
}

39 DANIEL, Claudia, “Medir la moral pública...”, ob. cit., p. 160. 
"ha[n] tropezado fatalmente con los inconvenientes insalvables de la falta de datos estadísticos demostrativos del estado y desarrollo de la delincuencia en el territorio de la República y del movimiento judicial en materia penal [...]. Todos -continuaba- han debido lamentar profundamente la ausencia de fuentes seguras de información"40.

Por su parte, en 1910 el notable jurista Rodolfo Rivarola señalaba la carencia de "estadísticas útiles para conocer la positiva delincuencia de los menores en relación al número total de la población infantil”41.

Como observa Lila Caimari, su fiabilidad como fuente de información es dudosa, pero las cifras compiladas por la Policía de la Capital "son las que usan los contemporáneos para construir sus propios diagnósticos” y también las únicas de que disponemos al día de hoy para "componer un panorama de las tendencias" delictivas. Hoy sabemos que las cifras de la estadística policial reflejan solamente los delitos denunciados, "que constituyen una selección muy desigual de las transgresiones cometidas" 42 . Asimismo, no hablan de las denuncias tal y como fueron hechas por los damnificados, sino que constituyen una reelaboración de esas denuncias: operan sobre prácticas muy variadas encasillándolas "en definiciones institucionales cargadas de presupuestos que sesgan la percepción”. Las clasificaciones delictuales (robo, hurto, lesiones, agresión, etc.) son etiquetas que enmascaran tras de sí una multiplicidad de prácticas y situaciones que los procedimientos administrativos catalogan con fines estadísticos. A su vez, los datos compilados no pueden considerarse como series homogéneas, dado que la información fue incorporada de manera irregular y variable a lo largo del tiempo. Finalmente, la estadística delictiva llevada por la policía "arrastra los problemas propios de toda representación institucional que a la vez es reflejo de su propia eficacia, medida de su labor a los ojos del ministerio al que informa y por ende objeto de muchas manipulaciones" 43 . Con todo, estas observaciones no invalidan de plano la información estadística, sino que nos advierten sobre el perjuicio de confiar en ella ciegamente.

\footnotetext{
$4^{40}$ BALLVÉ, Antonio, Primer censo carcelario. Resultados generales, Buenos Aires, Talleres Gráficos de la Penitenciaría Nacional, 1910, p. 7.

${ }^{41}$ RIVAROLA, Rodolfo, Derecho penal argentino, Buenos Aires, Hijos de Reus, 1910, p. 412.

42 Como señaló agudamente Daniel, las estadísticas delictivas oficiales eran mucho más sensibles a las conductas de los sectores marginados de la sociedad, que a las protagonizadas por los sectores más acomodados y los funcionarios públicos. En este sentido, ejemplifica la autora, la estadística policial contabilizaba los desacatos a la autoridad pero no los abusos de autoridad. DANIEL, Claudia: "Medir la moral pública...", ob. cit., p. 159.

43 CAIMARI, Lila, Mientras la ciudad duerme..., ob. cit., p. 29.
} 
Atendiendo a los datos disponibles en el Anuario Estadístico de la Ciudad de Buenos Aires, con todas sus limitaciones y las precauciones expresadas, es posible construir una imagen en el tiempo del movimiento criminal de menores para el período 1882-192344.

\section{Gráfico 3. Aprehensiones policiales según grupos de edad. Ciudad de Buenos Aires, 1882-1923}

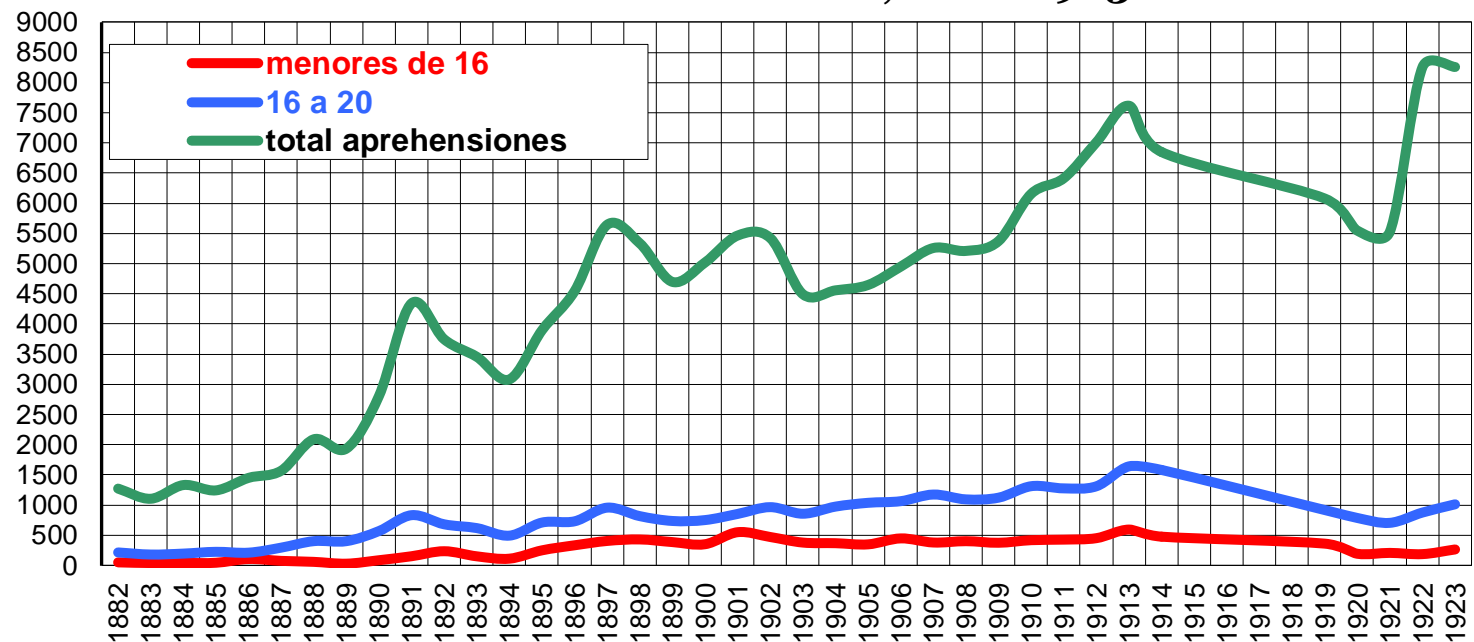

Fuente: elaboración propia en base a los datos aportados por el Anuario para los años de referencia.

El Gráfico 3 desglosa, para el período 1882-1923, las aprehensiones policiales distinguiendo su comportamiento según grupos de edad. Como se puede observar, las aprehensiones de menores de 20 años sufren bastantes menos oscilaciones y picos que el conjunto, aunque la franja correspondiente a los menores entre 16 y 20 años registra movimientos ascendentes, aunque menos pronunciados, en los momentos “críticos" (1890-1, 1897, 1901-2, 1910, 1913, 1922). Por el contrario, la evolución de las aprehensiones de menores de 16 años, observa mayor estabilidad.

\footnotetext{
44 Como dijimos anteriormente, el Anuario Estadístico de la Ciudad de Buenos Aires se publicó de manera casi ininterrumpida desde 1891 hasta 1914, a excepción del año 1909, cuando el Censo municipal practicado ese mismo año reemplazó la edición anual. De manera que 1891-1914 es el primer ciclo del Anuario que estuvo bajo la dirección del renombrado estadístico Alberto B. Martínez. El tomo siguiente (XXV) es una compilación estadística correspondiente al período 1915-1923 y fue editado en el año 1925. Sin demasiadas explicaciones acerca de ese salto temporal, el nuevo director de la Dirección General de Estadística Municipal, Julio L. Bustamante, aclaró que esta compilación incluía resúmenes estadísticos de casi todas las materias desglosados anualmente para el tramo 19151923. La excepción fue el capítulo dedicado a "Movimiento criminal y policial", "por haber carecido de los originales en algunos casos y por algunas modificaciones introducidas en la estadística municipal en otros" no se incluía el desglose del movimiento criminal desde 1915, sino las cifras del último quinquenio, esto es, 1919-1923. Anuario Estadístico de la Ciudad de Buenos Aires. Resúmenes de los años 1915 a 1923, Año XXV, Buenos Aires, Briozzo Hnos., 1925, p. 237. Claudia Daniel ha señalado, a su vez, que el nuevo director de la agencia no consideraba justificada la extensión que se había dado a esta cuestión en ediciones anteriores (p. 163).
} 
El Gráfico 4 relaciona la participación porcentual de la población de 5 a 14 años en el total de la población de la ciudad de Buenos Aires para el período 18871920, con la participación porcentual de los menores de 16 años en el total de las aprehensiones. Allí se puede observar que, excepto en la década de 1890, el porcentaje de menores de 16 años aprehendidos mantiene su relación con el movimiento poblacional. Notemos, a su vez, que en la década de 1890 crece sustancialmente la cantidad de menores aprehendidos, llevando al doble su participación en el total en la primera parte de la década y sosteniendo esta tendencia en la segunda mitad. Sin embargo, la tendencia al alza se corta con el nuevo siglo, cuyas dos primeras décadas registran un nivel estable de participación de los menores de 16 años en el total de las aprehensiones policiales.

Gráfico 4. Participación de los menores de 16 años aprehendidos en la población

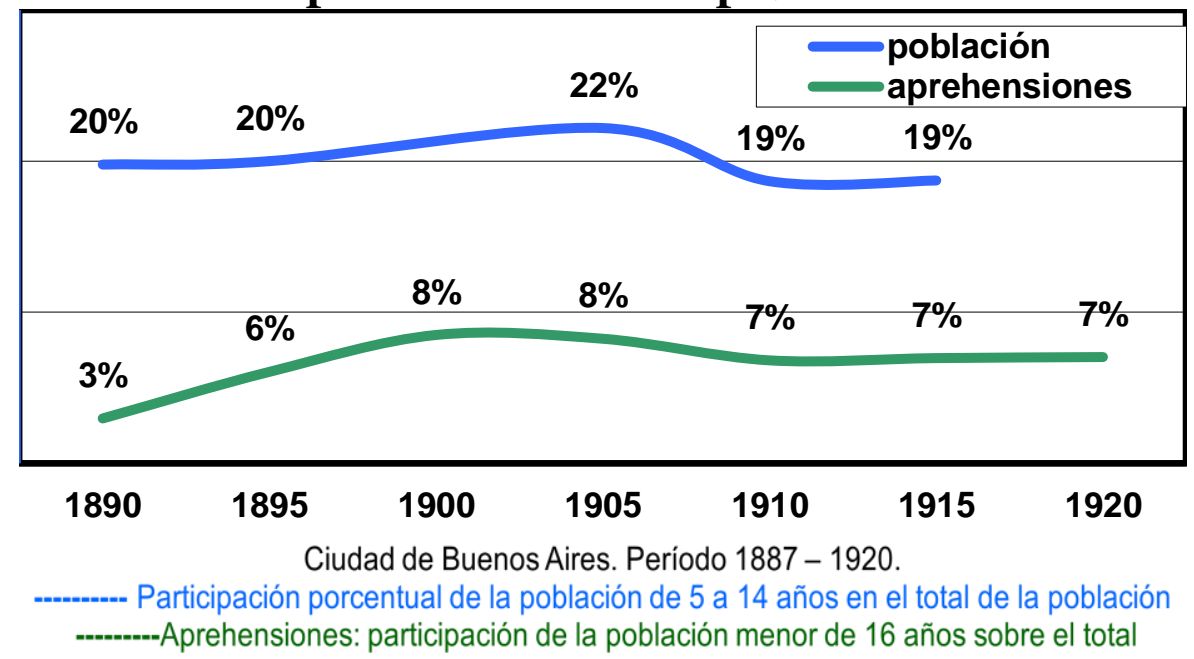

Fuente: elaboración propia en base a los datos aportados por el Anuario para los años de referencia.

Este movimiento criminal apunta a un proceso que los contemporáneos no registraron en toda su magnitud. El sobresalto de la estadística delictiva de menores de 16 años de la última década del siglo XIX coincide, no casualmente, con dos fenómenos de la historia social del delito vinculados entre sí, pero diferenciables. Por un lado, en la década de 1890 se produce una ampliación sustantiva de la capacidad de encierro estatal de menores de edad. Todo el decenio registra la apertura de instituciones públicas (y también particulares) de confinamiento y corrección de 
niños, niñas y jóvenes45. Por otra parte, la última década del siglo registró una activa intervención policial sobre la infancia urbana: de entonces data una densa red de prohibiciones y normas ordenadoras de la presencia infantil en la ciudad (que no jueguen en las calles, que no remonten barriletes, que no estén en las calles por las noches ni en horario escolar, que no estén en los bares, fondas, tabernas y casas de juego, que no contravengan los edictos sobre venta ambulante). La policía buscó regular, controlar, vigilar desde el juego hasta la sociabilidad infantil, desde la forma de circular hasta los modos de ganarse la vida ${ }^{46}$.

Considero que en la articulación de estos dos fenómenos se halla la explicación de ese salto cuantitativo (pero también cualitativo) de la delincuencia infantil y juvenil de la ciudad de Buenos Aires: la ampliación de la capacidad de secuestración del Estado en relación a menores registrada en la década de 1890 coincide con la casi triplicación de la participación de los menores de 16 años en el total de las aprehensiones policiales y con la profusión de nuevos edictos, disposiciones y normas policiales que apuntaban a la vida cotidiana de la infancia plebeya porteña.

\section{Reflexiones finales}

En 2001 se publicó La niñez ajusticiada, un libro sobre la situación a la que estaban sometidos miles de niños y jóvenes bajo tutela estatal en el marco de la Ley de Patronato de Menores que rigió en nuestro país hasta 2005. Esa obra tenía un epílogo ingeniosamente titulado "El sainete de los datos". Allí argumentaron sus autoras que

\footnotetext{
45 Ateniéndonos solo a los dedicados a menores de edad (o que, sin ser exclusivos, de todos modos los alojaba) encontramos que en 1890-1891, se llevó adelante la prueba piloto de la Cárcel Correccional de Menores; en 1893, se alzó Alcaidía de $2^{\circ}$ división o Depósito de Contraventores "24 de Noviembre"; en 1894, el Instituto de Menores "Manuel Aguirre" del Patronato de la Infancia; hacia 1895, el Refugio Nocturno y la Escuela de Artes y Oficios del Patronato de la Infancia; en 1897, el Asilo San Miguel para mujeres contraventoras (que también encerraba a menores de edad dependientes de las Defensorías) y en 1898, el primer reformatorio argentino: la Casa de Corrección de Menores Varones.

${ }^{6} 6$ Trabajé ambos fenómenos en FREIDENRAIJ, Claudia, "Intervenciones policiales sobre la infancia urbana porteña (1890-1920)", Dossier «Gobierno de la ciudad, policía y poder municipal en Buenos Aires, 1870-1920» Diego GALEANO y Cristiana SCHETTINI (coords.), Revista Historia \& Justicia, N $^{\circ}$ 6, Santiago de Chile, abril de 2016, pp. 164-197. ISSN 0719-4153. Disponible en: http://revista.historiayjusticia.org/wp-content/uploads/2016/05/RHyJ-6-h-articulo-FreidenraijFINAL.pdf y "En la leonera. El encierro policial de menores en Buenos Aires, 1890-1920", Revista de Historia de las Prisiones, $\mathrm{N}^{\circ} 1$, pp. 78-98. Disponible en http://www.revistadeprisiones.com/wpcontent/uploads/2015/11/4 Freidenraij.pdf.
} 
"la incoherencia entre los datos aportados por las diferentes agencias de control social sobre los mismos problemas, las dificultades para establecer mediciones confiables sobre cuántos, quiénes y cuáles son los 'sujetos' que ameritan una legislación específica, en fin, las abiertas contradicciones entre informaciones procedentes de diferentes fuentes, hacen difícil pensar en un diseño coherente de política pública para este segmento etáreo que no rinda homenaje al sensacionalismo de la prensa sino que se ciña a la 'realidad'"47.

Y llamaban la atención sobre "el enorme andamiaje discursivo invertido en modelar una opinión pública favorable al endurecimiento de las penas y la 'rebaja' en la edad de imputabilidad penal, tiene bases absolutamente endebles" 48 .

Estas reflexiones nos interpelaron directamente. ¿Cómo se construyen políticas públicas destinadas a punir a determinados sectores de la sociedad? ¿Bajo qué argumentos se justifican y legitiman? ¿En qué medida los datos aportados por un aparato estadístico de reciente construcción fueron funcionales al nacimiento y multiplicación de los espacios de encierro exclusivos para menores de edad? ¿Existe una correlación entre la información producida por intelectuales y agencias oficiales sobre la criminalidad y los criminales y las decisiones públicas sobre qué hacer con ellos? Estas son algunas de las preguntas que subyacen en este trabajo. Por otra parte, la obscena continuidad de la confusión, las contradicciones y los desórdenes estadísticos y políticas estatales entre ayer y hoy funcionan como advertencia de la necesidad de problematizar la cuestión.

Independientemente de cómo se comportaron los fenómenos reales de la delincuencia infantil, la vagancia y el abandono de niños, lo cierto es que a lo largo del período se produjo la construcción de una demanda de intervención que funcionó a repetición. En este sentido, las observaciones de las oscilaciones estadísticas, cuantificables aun con las deficiencias y problemas de las mediciones disponibles, se volvieron secundarias en relación a otras estrategias argumentales que apuntaban a una magnitud ascendente de niños peligrosos/en peligro; una amenaza social

47 GUEMUREMAN, Silvia y DAROQUI, Alcira, La niñez ajusticiada, Buenos Aires, Ediciones del Puerto, 2001, pp. 14-15.

${ }^{8}$ Idem, p. 15, negritas en el original. 
creciente y una urgencia que -en boca de los contemporáneos- se planteaba en espejo con la desidia oficial49.

La estadística fue un medio, entre otros, para procurar entender la fisonomía y la naturaleza de una subcultura delictiva que, se afirmaba, crecía día a día sin pausa y con relativa prisa. Convivió con otras formas de inteligibilidad de ese fenómeno, como las historias criminológicas, los estudios etnográficos, las observaciones de calle y de "laboratorio". Una evaluación de estos recursos en la confección de diagnósticos acerca de la criminalidad infantil, por un lado pone de manifiesto la primacía del impresionismo aun cuando se recurra al dato estadístico y, por otra parte, destaca las bases empíricamente endebles de ese supuesto crecimiento de la delincuencia precoz.

Como sostiene Daniel, pese a la debilidad de las estadísticas en términos técnicos es preciso reconocerles cierta eficacia en términos simbólicos, en la medida en que contribuyeron a modelar "un código de lectura de la realidad socialmente válido" ${ }^{\circ}$. Esa grilla interpretativa no sólo puso en el centro de los análisis del universo delictivo la cuestión inmigratoria y la decadencia moral de la Nación, sino también la convicción de que la criminalidad infantil estuvo en ascenso a lo largo de tres décadas y que el Estado debía intervenir de manera urgente para extraer el mal de raíz. Armando Claros condensó esa forma de leer el fenómeno criminal en su informe de octubre de 1912 sobre organización carcelaria en las siguientes palabras: "la delincuencia avanza, la reincidencia aumenta, la proporción de jóvenes y adolescentes es lamentablemente cada vez mayor, y la inmigración de extranjeros traduce sus cifras progresivas en marcados contingentes de transgresores que

\footnotetext{
49 En 1917, Juan P. Ramos concluía, al desmenuzar la estadística policial sobre la delincuencia precoz de 1915, que "las cifras no son como para que nuestra sociedad contemple indiferente el desarrollo de este enorme peligro futuro de la delincuencia actual de los menores [...]. Las calles de Buenos Aires se van llenando, cada vez más, de niños menores de diez años que piden limosna hasta las más altas horas de la noche. Los vendedores de diarios, menores en su inmensa mayoría, no saben del todo o saben apenas qué es un hogar. La prostitución infantil reviste un carácter cada vez más alarmante. Sin embargo, la acción oficial es casi nula”. RAMOS, Juan P., La codificación penal argentina. El proyecto de 1906 ante las nuevas tendencias del derecho penal en formación, Buenos Aires, Talleres Gráficos del Ministerio de Agricultura de la Nación, 1917, pp. 54-55.

50 DANIEL, Claudia, “Medir la moral pública...”, ob. cit., p. 163.
} 
pueblan las prisiones" 51 . He aquí las líneas maestras que, a grandes trazos, moldearon las visiones sobre la cuestión criminal a principios del siglo XX.

Finalmente, quisiéramos llamar la atención sobre el hecho de que la estadística del movimiento criminal no agota al universo de niños y jóvenes que caía en manos de la policía. Estos guarismos no incluyen a los niños que la policía levantaba en la calle por vagancia ni tampoco muchos de los que entraban a las comisarías de manera más o menos regular, ya conocidos por los oficiales, considerados "abandonados" y a menudo puestos a disposición de las Defensorías de Menores. Así, las estadísticas dejan fuera de la contabilización a una densa zona gris compuesta de chicos y muchachitos no necesariamente delincuentes ni contraventores, pero sí sujetos de vigilancia y diverso grado de represión policial. Habitantes de los márgenes sociales, estos menores se insertan en el área también marginal de intervención policial que no está muy reglamentada ni muy atravesada por reglas ni procedimientos y, por lo tanto, escapa a su registro estadístico. Quizás se deba justamente a este universo más nebuloso que queda fuera de toda cuantificación el hecho de que los diagnósticos acerca de la delincuencia precoz hicieran un uso más bien accesorio de la estadística.

\section{Fuentes}

\section{Publicaciones periódicas}

Anales del Patronato de la Infancia, Buenos Aires, Años 1892, 1894, 1899.

La Nación, Buenos Aires, Años 1897, 1898, 1900, 1901.

Tribuna, Buenos Aires, Año 1900.

Caras y Caretas, Buenos Aires, Año 1908.

Sherlock Holmes, Buenos Aires, Año 1911.

\footnotetext{
${ }_{51}$ Ministerio de Justicia e Instrucción Pública. Proyecto de Reformas Carcelarias. Informe de la comisión especial compuesta por Diego González, Armando Claros y Catello Muratgia, Buenos Aires, Talleres Gráficos de la Penitenciaría Nacional, 1913, p. 37.
} 
INGENIEROS, José, "Los niños vendedores de diarios y la delincuencia precoz", Archivos de psiquiatría, criminología y ciencias afines, Tomo VIII, 1908, pp. 329-348

BALLVÉ, Antonio, "La criminalidad en la Capital en los últimos diez años", Revista de Policía, $\mathrm{N}^{\circ} 233,1^{\circ} / 2 / 1907$.

Anuario Estadístico de la Ciudad de Buenos Aires. Resúmenes de los años 1915 a 1923, Años 1891 a 1923

\section{Tesis}

BULLRICH, Eduardo J., Asistencia social de menores, Tesis presentada a la Facultad de Derecho y Ciencias Sociales de la Universidad de Buenos Aires para optar al grado de Doctor en Jurisprudencia, Ed. Jesús Menéndez, Buenos Aires, 1919

GACHE, Roberto, La delincuencia precoz, Buenos Aires, J. Lajouane \& Cía., 1916

DELLEPIANE, Antonio, Las causas del delito. Tesis para optar al grado de Doctor en Jurisprudencia. Facultad de Derecho y Ciencias Sociales. Buenos Aires, Imprenta de Pablo Coni e Hijos, 1892.

\section{Documentos institucionales}

Memorias del Ministerio de Justicia e Instrucción Pública, Año 1906.

BALLVÉ, Antonio, Primer censo carcelario. Resultados generales, Buenos Aires, Talleres Gráficos de la Penitenciaría Nacional, 1910.

Ministerio de Justicia e Instrucción Pública. Proyecto de Reformas Carcelarias. Informe de la comisión especial compuesta por Diego González, Armando Claros y Catello Muratgia, Buenos Aires, Talleres Gráficos de la Penitenciaría Nacional, 1913.

\section{Otras fuentes impresas}

RIVAROLA, Rodolfo Derecho penal argentino, Hijos de Reus, Buenos Aires, 1910.

LANCELOTTI, Miguel A. La criminalidad en Buenos Aires, al margen de la estadística (1887 a 1912), Córdoba, Buena Vista Ed., 2012 [1912].

BULLRICH, Eduardo J. y GACHE, Roberto, Código de menores. Anteproyecto e informe presentado al Señor Ministro de Justicia e Instrucción Pública Dr. Carlos Saavedra Lamas, Buenos Aires, Talleres Gráficos de la Penitenciaría Nacional, 1916.

RAMOS, Juan P., La codificación penal argentina. El proyecto de 1906 ante las nuevas tendencias del derecho penal en formación, Buenos Aires, Talleres Gráficos del Ministerio de Agricultura de la Nación, 1917. 


\section{Bibliografía}

CAIMARI, Lila, Apenas un delincuente. Crimen, castigo y cultura en la Argentina, 1880-1955, Buenos Aires, Siglo XXI, 2004.

CAIMARI, Lila, Mientras la ciudad duerme. Pistoleros, policías y periodistas en Buenos Aires, 1920-1945, Buenos Aires, Siglo XXI, 2012.

DANIEL, Claudia, "Medir la moral pública. La cuantificación policial del delito en Buenos Aires, 1880-1910", Estatística e Sociedade, № 1, Noviembre de 2011, Porto Alegre, pp. 149-165.

FOUCAULT, Michel, Vigilar y castigar. Nacimiento de la prisión, Buenos Aires, Siglo XXI, 2006 [1975].

FREIDENRAIJ, Claudia, La niñez desviada. La tutela estatal de niños pobres, huérfanos y delincuentes. Buenos Aires, ca. 189o-1919, Tesis de Doctorado en Historia, Facultad de Filosofía y Letras, Universidad de Buenos Aires, 2015.

FREIDENRAIJ, Claudia, "En la leonera. El encierro policial de menores en Buenos Aires, 1890-1920", Revista de Historia de las Prisiones, $\mathrm{N}^{\circ} 1$, 2015, pp. 78-98. Disponible en http://www.revistadeprisiones.com/wpcontent/uploads/2015/11/4 Freidenraij.pdf

FREIDENRAIJ, Claudia, "Intervenciones policiales sobre la infancia urbana porteña (1890-1920)", Dossier "Gobierno de la ciudad, policía y poder municipal en Buenos Aires, 1870-1920", Diego GALEANO y Cristiana SCHETTINI (coords.), Revista Historia \& Justicia, $\mathrm{N}^{\circ}$ 6, Santiago de Chile, abril de 2016, pp. 164-197. ISSN 0719-4153. Disponible en: http://revista.historiayjusticia.org/wp-content/uploads/2016/05/RHyJ-6-harticulo-Freidenraij-FINAL.pdf

GONZALEZ BOLLO, Hernán et al., 125 años de la estadística porteña, Ciudad de Buenos Aires, Gobierno de la Ciudad Autónoma de Buenos Aires. Dirección General de Estadísticas y Censos, 2015.

GUEMUREMAN, Silvia y DAROQUI, Alcira, La niñez ajusticiada, Buenos Aires, Ediciones del Puerto, 2001.

JONHSON, Lyman (ed.), The Problem of Order in Changing Societies. Essays on Crime and Policing in Argentina and Uruguay, 1750-1940, University of New Mexico Press, 1990.

KIRK BLACKWELDER, Julia y JOHNSON, Lyman, "Changing Criminal Patterns in Buenos Aires, 1890 to 1914", Journal of Latin American Studies, Vol. 14, No 2, 1982, pp. 359-379.

KIRK BLACKWELDER, Julia y JOHNSON, Lyman, "Estadística criminal y acción policial en Buenos Aires, 1887-1914”, Desarrollo Económico, N93, Vol. 24, Abril-Junio/1984. 
SALVATORE, Ricardo, "Los crímenes de los paisanos: una aproximación estadística", Anuario del IEHS "Prof. Juan Carlos Grosso", N²12, Tandil, UNCPBA, 1997, pp. 91-100.

SALVATORE, Ricardo, "Patrones de sentencias en la Argentina moderna, 18781948”, II Jornadas Nacionales de Historia Social, La Falda, Córdoba, Mayo de 2009.

SALVATORE, Ricardo, "Usos científicos en La mala vida de Eusebio Gómez" en Osvaldo BARRENECHE y Ricardo SALVATORE, El delito y el orden en perspectiva histórica, Rosario, Prohistoria, 2013, pp. 99-120.

SCARZANELLA, Eugenia, Ni gringos ni indios. Inmigración, criminalidad y racismo en la Argentina, 1890-1940, Buenos Aires, UNQui, 1999.

SOZZO, Máximo, "«Los exóticos del crimen». Inmigración, delito y criminología positivista”, Delito y sociedad. Revista de Ciencias Sociales, Año 20, $\mathrm{N}^{\circ} 32$, 2011.

VILLALTA, Carla, Entregas y secuestros. La apropiación de 'menores' por parte del Estado, Tesis de Doctorado, UBA, 2006.

ZAPIOLA, Carolina, La invención del menor. Representaciones, discursos y políticas públicas de menores en la ciudad de Buenos Aires, 1882-1921, Tesis de Maestría, Buenos Aires, UNSAM, 2007. 